\title{
Types of learning identified in reflective energy diaries of post-graduate students
}

\author{
Dan van der Horst $(\mathbb{D})$ Sam Staddon
}

Received: 6 January 2017 / Accepted: 14 November 2017 / Published online: 14 December 2017

(C) The Author(s) 2017. This article is an open access publication

\begin{abstract}
Engagement with students about social and environmental dilemmas can be an important pathway to help to transform attitudes and behaviours in society over time. This paper seeks to further the links between research on energy behaviour and demand-side management in the home with educational research about learning processes. We analyse 'free-form' energy diaries written by 33 masters students, identify the different types of knowledge and insights that students have sought to obtain during this self-led exercise and find that we can link that back to different types of learning recognised in education studies literature, namely situated learning, social learning, reflective learning and experimental/action learning. We argue that these different forms of learning are interlinked and can be relevant for the development of both environmental citizenship and 'living lab' approaches. Embedding all these different forms of learning in both research and teaching on energy demand management has the potential to yield rapid, co-produced research insights as well as useful points for action for students, building managers and other relevant actors in college towns and student service provision. It could also help the next generation of graduate professionals to become more
\end{abstract}

\footnotetext{
D. van der Horst $(\bowtie) \cdot$ S. Staddon

Research Institute of Geography and the Lived Environment, School of Geosciences, University of Edinburgh, Drummond Street, Edinburgh EH89XP, Scotland

e-mail: dan.vanderhorst@ed.ac.uk

S. Staddon

e-mail: sam.staddon@ed.ac.uk
}

energy aware through their own personal experiences and thus potentially more open towards lower energy choices in material investment and daily practices in subsequent stages of their lives.

Keywords Energy literacy · Learning theory · Energy use $\cdot$ Daily life $\cdot$ Students

\section{Introduction}

Academic writings about the multiple invisibilities of energy (Burgess and Nye 2008) and the multiple dimensions of energy literacy (DeWaters and Powers 2011; Van der Horst et al. 2016) draw attention to the nature of energy as a vital, complex and hard-to-manage resource in daily life. Whereas in other domains of daily life, the knowledge and decisions of individuals can be restricted (e.g. in the work place where energy consumption behaviour of individuals may be designed-out), there is also the scope for training people to become more conscientious consumers, for example by offering motorists (who already have been skilled up through a combined theoretical and practical driving test) the opportunity to also train themselves in 'eco-driving' (Sivak and Schoettle 2012). Homes and offices are a far more complex socio-technical system than the car. A lot of research has been focused on the conditionality and limitations of behavioural change and the (limited) extent of energy savings that this may bring (Darby 2006; Ehrhardt-Martinez et al. 2010; Hargreaves et al. 2010). But although live monitoring with smart meters 
holds the promise of improved access to energy consumption data, it also raises new questions of how this data is converted to knowledge and the importance of learning and training to make sense of digital data about mundane (energy consuming) actions and (energy utilising) objects in daily life. Moreover, the way in which newly obtained knowledge about energy may feed back into possible changes in attitudes and behaviour is dependent not only on the situated nature of that new energy knowledge but also on the process by which that new knowledge was gained. To focus largely on the relationship between metering feedback and consumptive behaviour is to miss out on wider questions about understanding the material complexities and social dynamics that people experience in the built environment as they negotiate different phases of their lives.

Studies of energy consumption in the home and the potential for demand reduction are often focused on particular groups in society, e.g. elderly people (Burholt and Windle 2006), home-owning families (Amecke 2012) and people living in social housing and/or in energy poverty (Jenkins 2010). This study focuses on university students, a relevant choice for the following reasons. Students should be a key target group for energy demand reduction because they are future middle and high earners, a 'hard to reach' category when it comes to reducing energy consumption through price signals. Where the energy literacy of university students is found lacking, it is likely that others will struggle even more. Students have to negotiate a range of different types of build environments, thus mirroring the experiences of several other groups; as a transient group with limited financial resources, they depend on the provision of university flats or are exposed to the private rental sector where housing quality may be low. They spend a significant proportion of their time in shared spaces (to study, for leisure) where they have little say about material aspects but have to negotiate and maintain social relations. In short, as they transition from teenage dependents to middle-class citizens, university students gain important knowledge and formative experiences. They may become more removed from the energy-intensive practices of their parents and learn new consumptive practices; hence, they are a key group to engage with if we want the next generation to be more successful in cutting back on energy consumption. By working with students to explore the wider aspects of energy consumption in daily life, this study sets out to address the following research question: what kinds of learning need to take place in order to enable citizens to better understand the patterns of domestic energy use and (subsequently) seek to reduce energy consumption in the domestic sphere?

We explore students' engagement with energy consumption through the use of free-form 'energy diaries'. We seek to understand the pedagogical role of such reflective diaries and to contemplate its potential as a tool for promoting behaviours that are attentive to energy consumption. The paper thus offers a novel contribution to wider literature on energy demand management, moving beyond interventions based on the provision of energy feedback to instead consider broader forms of learning around energy practices.

We next provide a brief review of the literature within which this study is placed, considering both energy practices and opportunities for reflective learning. The subsequent section explains our empirical case study with masters students at the University of Edinburgh, who participated in a number of different exercises with regard to domestic energy use. We present the results in terms of the thematic areas of improved energy literacy experienced by the participants. We then discuss the types of learning which we were able to observe during the exercise, and we finish with a reflection on the usefulness and limitations of engaging with university students about domestic energy use, as part of a wider agenda on improved energy literacy and the encouragement of behavioural change towards lower energy living in more affluent societies.

\section{Background}

The challenge of promoting a less energy-intensive society is a huge one. Much of the literature on energy demand management in the home and workplace focuses on how to alter occupant behaviour, given the large variation this causes in building energy use, even between identical buildings and spaces. Behaviour change interventions have adopted multiple strategies to encourage energy-saving behaviours including education, persuasion, incentivisation, role models, physical restructuring of environments and deeper 'enabling' forms of engagement (Kollmus and Agyeman 2002; Osbaldiston and Schott 2012; Lo et al. 2012). A persistently popular approach is the provision of energy feedback, i.e. information on an individual's or group's energy consumption, allowing them to alter their 
behaviour and thus reduce their consumption. Feedback may be indirect, in the form of energy bills, or continuous direct and real-time feedback through the use of, for example, in-home displays (IHDs) associated with smart metering.

Critics however accuse such approaches of being reductionist, implicitly adopting an 'information-deficit model' of human behaviour whilst ignoring wider social, cultural, material and political factors that influence and can constrain individuals' energy use. Alongside improved design and delivery of feedback, there is a need to explore alternative engagements and novel forms of participation in energy futures (Hargreaves 2017; Janda and Bull 2017). 'Speculative design' is seen as one alternative, encompassing 'feedback-like' devices which 'seek actively to resist, obscure and complicate narrow and instrumental framings of social and technological problems, such as those around energy demand' (Hargreaves 2017). Ways in which to engage users in learning about energy whilst paying attention to the wider dynamics of everyday life and practices of energy use are much sought after.

'Practices-that-use-energy' refer to the performance of activities such as showering or cooking, highlighting that energy use is socially and culturally mediated and organised, reflecting far more than simple decisions based on the quantity of energy consumption alone (Shove et al. 2007, 2012; Hargreaves 2011). Adopting such social practice theory concepts promotes an attention to the ingrained nature of energy use in everyday life, as well as the multiple environments in which its negotiation takes place - not just those formal spaces of engagement with IHDs but also the informal spaces in which personal decisions about bodily cleanliness are made for example. Strengers (2013) refers to what might be called 'practice feedback', encompassing 'social feedback', e.g. comments from friends or messages from the media; 'material feedback', e.g. when building design means that mechanical (rather than passive) heating or cooling is required; and 'embodied sensory feedback', e.g. toothpaste being solid due to the cold.

Others similarly refer to energy 'know-how', indicating the importance of embodied knowledge of household energy consumption and tacit knowledge gained through personal experience (Wallenborn and Wilhite 2014; Royston 2014; Burchell et al. 2012). Energy know-how is thought to build from personal, embodied experiences through physical routines and habits, for example drawing the curtains at night, as well as more conscious forms of knowledge, for example of a central heating programmer (Royston 2014). Energy knowhow is considered important in both the monitoring of and management of energy consumption, involving comprehension, choices and behaviours.

The social dimensions of energy learning are as important as individual, embodied personal experiences and are reflected in the trust householders put in their friends and family when trying to understand energy consumption and energy-saving behaviours, often preferring that to officially sanctioned forms of knowledge, such as from energy companies whom may be less trusted (Simcock et al. 2014). The importance of smart meter installers as intermediaries in learning around energy efficiency has recently been recognised (Darby and Liddell 2015; Wade et al. 2016, 2017), as has the importance of personal contact from researchers and others engaging with users around energy efficiency measures in the home (Gupta and Barnfield 2017). Within the workplace, the relevance of social dimensions in negotiating energy use and learning may be even more important than in homes (Staddon et al. 2016), reflecting social norms, group dynamics and a potential sense of community amongst employees (Bedwell et al. 2014; Leygue et al. 2014; Deline 2015; Dixon et al. 2015).

Learning about energy can clearly take multiple forms, as can teaching about it. The pedagogic foundations to teaching energy literacy are discussed in van der Horst et al. (2016), with attention for constructivist learning, i.e. through application of knowledge to real life (Hein 1991); transformative learning, i.e. through reflecting on particular perspectives (Mezirow 2009); and experiential learning, i.e. through direct experience. One way to encourage all three forms of learning is through fieldwork, i.e. direct engagement with or experience of an issue in the 'real world' and explicit reflection on this to various academic perspectives. Within a higher education context, fieldwork is particularly favoured by geographers and various forms of such active learning are adopted by those teaching energy geographies (Thoyre and Harrison 2016).

One way to assess fieldwork is through instructing students to complete a 'reflective journal' (Dummer et al. 2008) or 'learning journal' (Park 2003) on the field experience. A reflective field journal

“...requires students to observe and record information, then reflect upon issues... in order to make 
connections with wider theory and concepts, and subsequently generate new knowledge and understanding"

“...[is] distinct from a traditional field notebook/ diary in that [it is] not simply a repository for facts and details about the field trip; rather [it is] a vehicle to encourage critical reflection on the ... field experience" (Dummer et al. 2008, p. 462)

The reflective learning involved in producing such a journal encourages students to assume more responsibility for their own learning and to engage more actively with the material covered. As a consequence, students should understand more, learn more, remember more, enjoy it more and appreciate the relevance of what they have learned (Park 2003). Such 'deep learning' is contrasted with 'surface learning', where students passively receive facts and information without evaluating the information for themselves, for example as is typical in lecture settings. Reflective learning involves students having their own ideas and beliefs challenged by new experiences - such as through fieldwork - and thus, reflective learning is inherently unique to the student involved. Student's gender, age, culture, past profession, etc. will impact their path of learning, as will the classes they have taken, the papers and books that they have read and the topics and issues that most interest them. A reflective journal is thus also unique to the student, and as such, no one journal will be the same as any other. The journal is a demonstration of each student's own learning journey; it "is not meant to be a seamless and perfectly structured piece of writing, rather it is meant to capture thoughts, feelings and impressions as they emerge. The most interesting ones display interesting evidence of these processes at work" (Park 2003, p. 191). The scope for originality and innovation in journals is clearly high.

Traditionally, 'fieldwork' takes place in a distant environment that is new and thus challenging to the student. The challenge - and therefore the value - of fieldwork is said to emerge from a direct, active encounter with "the other" (Hope 2009). The focus of this paper concerns the role of fieldwork in promoting learning about energy amongst students within their own homes, i.e. not some distant land but their daily surroundings and not primarily 'the other' but mainly themselves. The home could be seen as a complex socio-technical system characterised by tensions between the original criteria and assumptions of the designers and the evolving wishes and experiences of actual inhabitants who come and go, finding or bringing a mixture of old and new energy-consuming or saving devices and negotiating between themselves how these are utilised in common spaces. It is no surprise that academics have found the home to be a highly suitable fieldwork location (Blunt and Dowling 2006; Brickell 2012), lending itself well to critical self-reflection in energy learning. It has been suggested that not only students but also researchers in academic institutions should engage in more reflective practices in order to promote explicit attention to the relationship between personal encounters with energy demand in researchers' own homes and their professional research on it (Staddon 2017). This is thought necessary so as to provide more creative and convincing accounts of what it takes to transform energy demand within our buildings; accounts which pay attention to our unique positionalities as well as the everyday and wider political dimensions of energy practices. In this context, promoting reflective learning amongst current students represents a forward-looking attempt to instil a sense of consideration and responsiveness both amongst those who will comprise the next generation of researchers, practitioners and policymakers, and amongst all other graduates, so as to support their development as 'environmental citizens' (see Hobson, 2013), or even more specifically for 'energy citizenship' (DevineWright, 2007). The above reflections chime with the wider debate about the need for Education for Sustainable Development (e.g. Venkataraman, 2009).

\section{Methodology}

The empirical data for our analysis is provided by 33 masters students at the University of Edinburgh who undertook self-guided 'fieldwork' activities in their own homes. About half the students were British, and the other half had 13 different nationalities from across the globe. Fifteen were female and 18 were male. Half the students lived in halls of residence (mainly the overseas students), and almost a third lived in private rented accommodation which they shared with one or more flatmates. The remainder of the students rented a flat with their partner (in one case with kids), owned their own property or (in once case) lived at home with their parents. The students had a variety of backgrounds, although natural sciences dominated. The energy diaries served as an introductory exercise for an optional course called 'Energy and Society' which aimed to look at 
society through the energy lens and was focused on social, societal and cultural aspects of technical change and energy transitions. Whilst the energy and society course and the energy diary exercise deliberately steered clear from an environmental rationale, the majority of the students on this course undertook a masters programme that was environmentally oriented.

The students were requested to keep an 'energy diary' for a whole week, in January (mid-winter). Energy diaries have been used before in research on energy demand management (Wilhite and Wilke, 1987; Cames and Brohmann, 2003), but our set-up was more neutral and akin to a 'reflective journal' (see previous section); the rationale for the diaries was that of 'understanding your own energy situation'. The format and contents were not specified. A minimum word count of 200 words/day was suggested upon request, but otherwise, students were encouraged to develop their own diary whichever way they wanted. During that same week, they were also requested to list all the appliances in their home, enter those in a spreadsheet and try to record the level of usage of these appliances, using a simple socket electricity meter. They also had to record electricity and gas meter readings on a daily basis.

In total, only 27 of the 33 student diaries were deemed suitable for coding and analysis. Several diaries were discarded because they were too short and of poor quality. Four diaries were produced on-line as blogs, one was produced as a video diary and one was produced as web pages, ordered by energy themes rather than by days. These more creative formats contained excellent visual and audio material, but they were less suited for coding. The spreadsheets were combined into a single file, and students were asked to identify 'archetypes' of energy consumers. Subsequent exercises (not the focus of this paper) included the testing of different (plausible) policy interventions, including, for example, the assessment of payback time for various household electrical appliances. For the purpose of this paper, it is only important to note the spreadsheets and the electricity and gas meters because they influenced some students in the writing of their energy diaries.

The diaries were coded manually and independently by the authors, followed by an exchange in which the types of recurring themes were agreed. A theme was deemed to be recurring if it was clearly found in two or more diaries.

We decided it would not be meaningful to report on the frequency of themes being mentioned in the diaries.
First of all, the group of participating students cannot be said to be a representative sample of some larger population. The frequency of some themes reflects simply the type of housing situation that participating students find themselves in (e.g. from specially built student flats with shared kitchens to single family households). Secondly, the individual diaries vary greatly in format, extent (word count), depth and style. Some themes are expressed in pictures in one diary and in text in another, whilst the longer diaries are by their nature more extensive in thematic content and the risk of repetition. Last but not least, the students were very culturally diverse; whilst we know that culture can be an important factor in the adoption of energy practices (see Wilhite et al. 1996), only the UK students constituted a larger national group, so beyond individual cases, opportunities for cultural comparisons were very limited.

\section{Results}

Some 24 frequently recurring themes were identified within the student energy diaries. Of those, we have ordered 22 into four thematic areas of energy use (Table 1). The other two recurring codes were related to emotions/feelings (e.g. annoyance, reluctance,

Table 1 Common themes (22) identified in the diaries, grouped into four categories

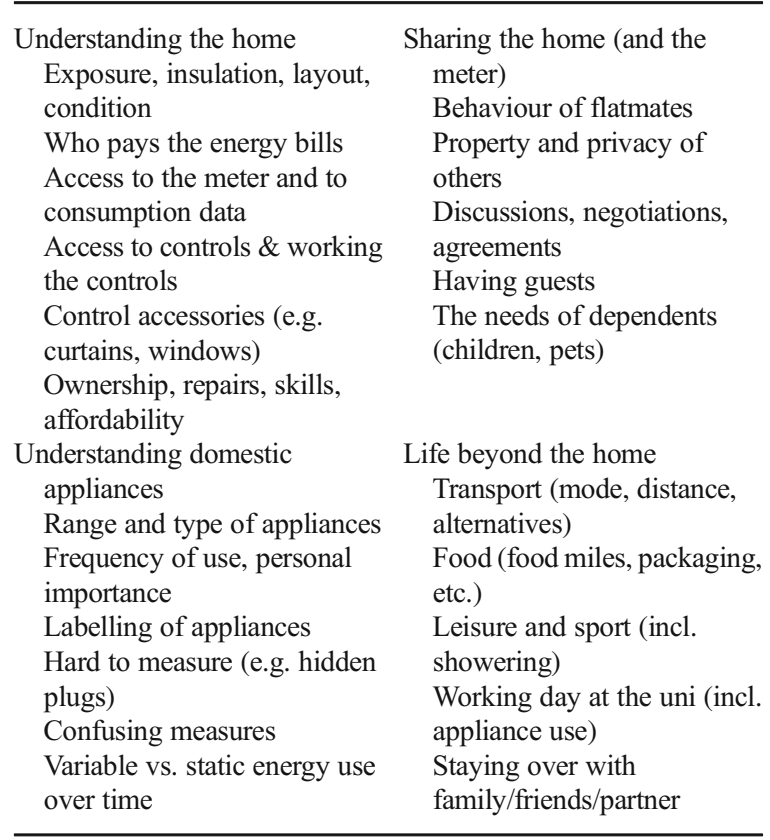


comfort, fun) and curiosity/reflection towards others and towards personal energy use. In the limited space of this paper, we are not able discuss each individual theme.

The four thematic areas could be characterised as two material domains, the home and the electric appliances found in the home, the social domain of sharing domestic spaces or domestic life with others and the practice domain of daily life beyond the home. Only a handful of very short diaries failed to reflect on all four of these thematic areas. The thematic area of 'appliances' was to a large extent framed by the spreadsheet exercise, as was the specific theme of accessing the meter, whilst the 7day period set for the diary captured a particular set of practices, such as going to campus most days, and specific tasks such as writing the daily diary entries. However, the other three thematic areas are largely or wholly representative of the boundaries the students explored and drew by themselves. It was particularly interesting to note how most students readily explored energy themes related to the body (exercise spaces and machines; food, its contents and supply chains) or taking place in shared spaces outside of the home. This suggests that for our students at least, 'the home' is not necessarily viewed as the singular and preeminent domain for engagement with questions of sustainable energy consumption in daily life.

In addition to the four main thematic areas discussed above, we also identified three cross-cutting issues:

\section{Pro-environmental framing}

Although we deliberately avoided any explicit rationale of the exercise beyond 'learning about "your" energy', the majority of students framed the exercise from an energy-saving perspective. Many students commented on their good and bad energy habits and how they may seek to improve on the latter. Writing the diary made students more aware of avoidable energy use, opening curtains so they did not need lights on, for example. Some students took to recording additional information, such as the time it took them to shower or to blow-dry their hair. Many commented on how they should try to cut back on some energy-intensive habits and why that may be difficult. Several students set themselves explicit energy challenges, e.g. cutting back on some foods that have a larger environmental and energy footprint. Others in the flat were evaluated from the same perspective of sustainable consumption, e.g. the partner being jokingly referred to as 'my energy nemesis' and complaints about the 'bad energy habits' of the dog that has learned how to open doors, allowing the heat to escape. Several students sought to discourage the 'bad' energy habits of flatmates and partners, by leaving notes, or other reminders to switch off lights and appliances.

\section{Inventories, knowledge gaps and known unknowns}

Students met with a range of difficulties in mapping and understanding their energy system and their energy use. Overseas students in halls of residence often had no idea what heating system they had. Their heating bills were included in the rent, and they struggled to find an energy meter in the building. They sent out emails and made calls to the building managers or letting agencies with limited rates of response. One persistent student obtained guidance on how to access extensive energy consumption data through the digital TV in the shared recreational area, a facility that was built in when the building was delivered but which had never been activated before. Several students staying in the same building asked the manager to give them a tour of the maintenance spaces of the building and the central boiler. They took photos of the screens displaying energy consumption for student flats, finding huge individual differences in consumption which the manager could not explain. Students in private rented accommodation who paid their own heating bills had difficulties relating their bills to meter readings. One student discovered that the electricity meter had been broken at least since the summer. Students in old, poorly heated flats in the city centre deployed a range of coping mechanisms to stay warm and not overspend on heating, from spending all day on campus (recharging their laptop several times) to going to the gym in the evening.

Some students did an inventory of all the lights in the house or made a video recording of the considerable collective effort required to get behind the fridge to plug in the socket meter. Many students struggled to understand why some appliances had such a variable use of electricity over time or why microwave ovens had an input rating (at the back) and a different output rating (on the settings on the front).

The exercise made students more critical of the service they received from their landlords. Those whose energy bills were inclusive in the rent were wondering if they were being overcharged. Although not asked to do so, a number of students tried to reconcile their electricity meter reading with the use of appliances as they had 
recorded on the spreadsheet, typically finding a gap of 50-80\% (representing heating and other appliances which they were not able to asses).

\section{System boundaries and social boundaries}

Although we only asked the students to keep a diary of domestic energy use, most students recorded at least some of their routines outside the home. Some of these activities were directly displacing energy consumption at home (e.g. avoided heating, lighting, charging of mobile appliances) or provided a thematic continuation of domestically important forms of energy consumption (e.g. eating). This suggests that students do not define their 'home' or 'domestic life' in a narrow sense; when it comes to energy consumption, they draw the system boundaries in accordance with daily student routines which extend from their room to the campus and other daily spaces or activities (e.g. bus, gym). On the basis of these observations, it would be possible to structure the thematic areas in different ways, e.g. social and material themes on the one hand and spatially definable themes on the other (the home and the rest, which could be further subdivided).

It was also notable that whilst most students were adopting a 'whole day' perspective towards their energy use which cuts across spatial boundaries, they were often drawing social boundaries more narrowly. Most of those who were cohabiting with their partner did not hesitate to report on the partner's behaviour, perhaps because they were sharing the same physical and social space on a permanent basis (and perhaps sharing finances too). However, flatmates and visitors tended to be treated differently. They were mentioned briefly, almost as exogenous factors, but their behaviour, property (appliances) and energy consumption were not reported in detail. Similarly, none of the students reported on their own behaviour when staying with friends or their partner. Despite often having their laptop with them, they treated these periods as a break from the duties of writing in their energy diary.

\section{Discussion}

Types of learning identified

Our methodology and the size and nature of the sample are not comprehensive enough to record 'all' types of learning which may be relevant to energy behavioural change. The limited sample size and the diverse and self-selected formats of the energy diaries do not allow us to rank the most important types of learning for action in a meaningful way. However, what we can do is try to identify a range of different types of learning experienced by participating students through the writing of their energy diaries (see Table 2).

First of all, it is important to recognise the situated and contextualised nature of the learning environment. The theory of situated learning (Lave and Wenger, 1991) examines how learning is shaped by the physical setting and social situation in which it occurs; by doing

Table 2 Identifying key type of learning experienced by students participating in the energy diary exercise

Mapping the domestic energy
labyrinth (situated learning)
- Finding out how the house
is heated (technology, fuel)
and what the 'normal' energy
bills are
- Searching for energy
meters, requesting energy
consumption data from land
lord or building manager
- Looking for the manuals of
the heating system and
built-in appliances
- Trying to get access to the
sockets of built-in appliances
- Finding out how the house
is insulated

Exchanging knowledge and negotiating participation in relation to shared spaces/resources/bills (social learning)

- Negotiating the social boundaries of what you can report about others in the household

- Providing feedback to others about their observed energy behaviour - Inviting others to participate in experiential learning - Collective target setting - Negotiate differential payments of shared energy bills or other ways to balance unequal use of energy in the house

- Agree on the purchase and/or adoption of energy-saving technology

The home as an energy lab Benchmarking and abstracting (experiential learning, action knowledge; examining learning)

- Experimenting with the heating controls

- Using socket meters to measure how much energy usage can be avoided

- Observing the behaviour of others (ethnographic, schematic)

- Designing intervention experiments (socio-technical innovations, reminders for (better) behaviour, target setting) scientific, global and comparative energy statistics (part of reflective learning)

- Looking up how appliances work and deteriorate

- Looking up the emission factors of grid electricity, for transport used, etc.

- Looking up environmental variables

- Looking up benchmarks for comparative performance 
their energy diaries simultaneously, our participating students became a community of practice, sharing problems, interpretations and insights as they went along together. However, the role of social setting is even more important when decisions have to be negotiated with others and there is scope for people to learn from each other. Where our masters students were able to persuade their partners or flatmates to participate in the mapping of energy appliances or in the behavioural experiments, a clear case of social learning was taking place (Bandura, 1977). The roots of social-learning theory date back to before the Second World War, but in energy demand-side management, the attention to social learning is quite recent and still growing (Leygue et al., 2014). Where students decided to look up further information or to reflect on their current energy use (largely by themselves), this is a form of benchmarking which relates to the 'abstracting knowledge' phase in reflective learning (Brockbank and McGill, 2007). And finally, where students decide to undertake particular experiments, try to set targets for themselves to achieve or attempt to reduce certain uses of appliances, we can speak of experiential learning (Kolb, 2014) or action learning (Pedler, 2011). The quick and effective feedback of energy data is of key importance in that respect.

These different types of learning are synergetic rather than mutually exclusive, and under any energy theme identified in the student diaries (Table 1), we find activities that relate to multiple types of learning. For example, the examination of food intake may require both situated and reflective learning, but when setting one's self a target (e.g. to eat less meat), experiential learning is likely to take place, whilst shared challenges go hand in hand with social learning.

There is a huge body of academic literature on the topic of learning, so for the sake of this paper, we limit ourselves to a relatively basic summary of the generic links which may be found between the different types of learning listed in Table 2. It could be argued that situated learning is the first form of learning which the domestic energy diaries stimulate and that the other three forms of learning represent particular forms of follow-up. We can find particular combinations of follow-up. For example, practical and social learning can go hand in hand, as changing practices in shared spaces and with shared appliances are negotiated and the subsequent experiences are shared. In student flats or family households alike, agreement may be forged on the basis of trust, social capital or shared values. However, in the case of the latter, there may be a need to resort to fact checking and benchmarking to provide the evidence base which can serve to translate shared values into agreed activities.

Effective learning is sequential. Learning can be conceptualised as a cycle (see Kolb, 2014; Brockbank and McGill, 2007; Abrahams and Singh, 2010) in which concrete experience (in this case, yielding situated learning) is followed by reflective observation which is in turn followed by the quest for abstract conceptualisation and generalisation, e.g. through establishing relevant benchmarks, which is in turn followed by experimentation. Within the empirical context of this paper, and dependent on the approaches taken by the students, social learning could take place at each stage of the cycle or could take place largely as a separate phase just before experimentation.

From learning to behavioural change

From the normative perspective of reducing the use of (non-renewable) energy, we would of course like to see (positive) experiential learning and action learning. Our findings indicate that situated learning and reflective learning are important prerequisites to effective behavioural change with regard to domestic energy use. Similarly, we would like to see pro-environmental and energy-saving behaviour being replicated by many people (not just our participating masters students), and this is where social learning is of particular relevance. Finally, and consistent with practice theory, our findings suggest that individuals perceive energy-saving behaviour within most routines of daily life across a variety of spatial, social and material settings. This observation contrasts with the typically compartmentalised engagement strategies that are developed top-down by government or industry, such as smart energy meters and feedback in the home.

For reasons of (insufficient) representativeness and ethics (we did not want to encourage students to deprive themselves), we did not try to assess the extent to which students were willing and able to reduce their energy use. We noted that different student groups were in very different positions to undertake energy-saving interventions. First of all, the students who were paying rent that was inclusive of heating bills had the least incentive to reduce energy use. In many cases, they also had very little access to information about their energy consumption. The majority of these students were also 
characterised by having relatively few electric appliances as personal possessions. An exercise with the students to identify different types of energy consumers based on the spreadsheets (see the 'Methodology' section), yielded three 'archetypes', from students with only their own laptop and mobile phone (typically overseas, male students) in fully furnished accommodation that included standard white goods and kitchen appliances (washing machine, dish washer, fridge, microwave, electric kettle, toaster) via a 'medium' archetype with more appliances (hair dryer, radio, more amenity lights) to an archetype of someone who had the full list of gadgets and appliances which can be associated with a longer term stay in a whole house and perhaps a better financial position over time which enabled the student to accumulate such appliances.

Students undertook some directed enquiries on the database of appliances under these three scenarios, including the scope for carbon emission reductions (greatest scope found in heating controls [where available and operational], length of showers and frequency of using the hot water kettle [including over-filling]) and the payback time to install and use more energy-efficient appliances. Installing energy-efficient light bulbs won in that category, but students were quick to point out that they would not be around long enough to benefit from this investment (i.e. LED lights lasting far longer than the student's tenancy), unless they then took these light bulbs with them upon departure. Other potential interventions were derived from existing policies, e.g. the recent phasing out of high-power vacuum cleaners under EU law. Students calculated that they did not use their existing vacuum cleaners long enough (even when multiplied by total number of flatmates) to recoup the investment into a new more low-powered machine. In short, students discovered that they were rather limited in what actions they could take which would directly reduce their energy consumption without eroding their quality of life.

Towards co-production and collective action

Students did however recognise that collective action could create a multiplier effect and that they could undertake other kinds of activities to influence greenhouse gas emissions. Recognising the computer and internet experiences of the current student generation, it took us little effort to encourage our students to creatively explore how social media could be used to spread ideas and motivations for reduction of energy consumption amongst the student population. We met with students who had designed their own environmental card games and elsewhere we worked with students to explore the potential of 'serious [computer] games' to provide feedback and motivation for energy-saving behaviour (Wood et al., 2014).

One suggestion from the students was that they could undertake collective political action by lobbying for particular changes on campus (e.g. more buildingintegrated renewables), in their halls of residence (e.g. better insulation, more accessible energy meters, more individual energy meters, better provision of [live] feedback on individual or appliance-specific energy use) and across the student population (e.g. informing new students on how to be more energy aware and critical of energy wastage). But stimulating or enabling students to become more pro-active environmental citizens raises questions about the role of other actors. We would argue that there are obvious synergies between student environmental citizenship and living lab approaches being developed on campuses (Evans et al., 2015). In the context of student accommodation, the living lab concept could be described as 'a combined lab-/household system, analysing existing product-service-systems as well as technical and socioeconomic influences focused on the social needs of people [...' (Liedtke et al. 2012).

As a final point of discussion, we wish to raise an old 'problem' in academic social science teaching. How should you teach a subject where the learner is (or could easily be) an object of the research? And how can you fully assess what knowledge and insights students have gained without paying attention to, and indeed encouraging, students to (also) study and learn about themselves? Moreover, academics should not compartmentalise and separate out their teaching and research activities, when instead they can create a shared learning environment where knowledge is successfully coproduced and which links active empirical research by the students to engagement with established and published academic knowledge. These questions are not asked very often, despite being of generic relevance to any area of social science where the subject relates directly to the lived experiences of the students in the class. Examples range from bodily experiences (e.g. health) and interactions with others (e.g. relationships) to interactions with the natural world (e.g. consumption of natural resources). Since knowledge of societal challenges (environmental or social) and motivation to 
address these are so intricately linked, academics are at the very least implicitly involved in shaping the societal values of their students. There are challenges for academics to decide if they should stop right there, just as they leave their students to ponder about what actions can be taken (a problem long recognised by the proponents of action research, see Brydon-Miller et al., 2003). Given the complex challenges society faces (which point to the limitations of established methods) and the clear pedagogic value of experiential learning, academics should look for new ways to work with their students, university structures and other relevant actors to experiment with new interventions, governance structures or business models, not just for the purpose of achieving direct improvements but even more for the purpose of co-producing actionable knowledge, sharing relevant skills and building coalitions for pursuing greater sustainability.

\section{Conclusions}

This paper adds to existing literature on energy literacy and the acquisition of knowledge and skills as prerequisites to the adoption of energy-saving measures in the home and in daily life. By analysing energy diaries of students living in diverse housing arrangements, this paper has drawn attention to the different types of learning that are required to increase people's energy literacy in domestic and everyday life. The students were by no means representative of wider society, but our findings about the different types of learning are actually strengthened by this particular selection bias; these students were above average interested in energy and environmental issues and yet the small effort of keeping an energy diary for a week has enabled them to experience and report a broad range of new learning experiences. We can therefore anticipate that these diverse learning experiences will be of even greater potential importance to other sections of society where there is potentially less energy knowledge and/or environmental interest.

The fleeting and impermanent nature of student life, the sharing of energy meters and the lack of ownership or control of their housing situation means that most students have a limited scope, influence and interest in improving the energy management of their temporary homes. On the other hand, this exercise has shown that within the participating group of students and their housing situations, we can already find most of the energy dilemmas they are likely to face in future life. Engaging with students about domestic energy consumption is thus a suitable avenue to nurture greater energy literacy for the next generation of middle- and high-income professionals who are less likely to be sensitive to energy costs per se and should therefore also be engaged in resource-efficient behaviour through other means.

Much of the learning recorded in the diaries reflected on the limits to personal action, e.g. due to limitations imposed by work/studies, non-ownership of the house and appliances and the needs and wants of other flatmates or household members. These factors could be seen as key elements of a broader conceptualisation of energy literacy in domestic and everyday life, and paying early attention to such limitations might open the door for more informed individual choices to be made in later phases of life, e.g. in relation to house selection/purchase, the installation of smart controls or even behaviour outside the domestic sphere. The fate of students in halls of residence and university spaces somewhat mirrors that of citizens in the work place; they are significant consumers of energy but are constrained in their agency to implement significant changes on their own. A large minority in society goes through several years of student life and the majority of us spend decades in the workspace, so these are important life phases and demographics when we seek to reduce the overall carbon footprint of society and they thus require our attention as researchers. Using the behaviour change wheel developed by Michie et al. (2014), we can see that in terms of 'sources of behaviour' to reduce energy use, our environmentally minded MSc students may have a stronger motivation than most people in the work place, but they arguably have less capacity and opportunity to change things. Our findings are hence also relevant to those who own student flats; to office, building and campus estate managers; and to college towns where a significant proportion of local houses are occupied by students; there is scope for improving the living conditions of students in private rented accommodation, empowering students to save energy and encouraging them to become more knowledgeable, committed and proactive environmental citizens as they look to find 
their place in the workforce and make their way in society.

More broadly, this paper draws attention to the complex nature of learning for behavioural change in relation to energy use. Our analysis of free-form energy diaries suggests that four types of learning need to take place in order for households to experiment with demand reduction, but also that engagement with energy does not have to stop at the front door. This provides pointers for further research, especially with regard to the design and evaluation of more holistic behavioural change programmes, but also for technology developers and smart appliances/home design; how can technology enable these different types of learning in different aspects of daily life? Efforts to 'design-out' user behaviour are likely to continue but are unlikely to achieve all by themselves the systemic reduction of avoidable energy consumption. Similar efforts need to be made to develop the pedagogic potential of energy-monitoring technology, i.e. technology to help energy users to become smarter, as well as more committed to make a (significant, cumulative) difference.

Acknowledgements First of all, we are of course indebted to the MSc students who participated in the energy diaries. We also gratefully acknowledge assistance from Cat Magill and Tim Kelly and financial support from the UK Engineering \& Physical Sciences Research Council (EPSRC) through the TEDDINET project (ref. EP/L013681) and the Smarter Households project (ref. EP/ K002635).

\section{Compliance with ethical standards}

Conflict of interest The authors declare that they have no conflict of interest.

Open Access This article is distributed under the terms of the Creative Commons Attribution 4.0 International License (http:// creativecommons.org/licenses/by/4.0/), which permits unrestricted use, distribution, and reproduction in any medium, provided you give appropriate credit to the original author(s) and the source, provide a link to the Creative Commons license, and indicate if changes were made.

\section{References}

Abrahams, A. S., \& Singh, T. (2010). An active, reflective learning cycle for e-commerce classes: learning about e-commerce by doing and teaching. Journal of Information Systems Education, 21(4), 383.
Amecke, H. (2012). The impact of energy performance certificates: a survey of German home owners. Energy Policy, 46, 4-14. https://doi.org/10.1016/j.enpol.2012.01.064.

Bandura, A. (1977). Social learning theory. Englewood Cliffs, NJ: Prentice Hall.

Bedwell, B., Leygue, C., Goulden, M., Mcauley, D., Colley, J., Ferguson, E., Banks, N., \& Spence, A. (2014). Apportioning energy consumption in the workplace: a review of issues in using metering data to motivate staff to save energy. Technological Analysis and Strategic Management, 26(10), 1196-1211. https://doi.org/10.1080/09537325.2014.978276.

Blunt, A., \& Dowling, R. (2006). Home. Routledge: Abingdon.

Brickell, K. (2012). 'Mapping' and 'doing' critical geographies of home. Progress in Human Geography, 36(2), 225-244. https://doi.org/10.1177/0309132511418708.

Brockbank, A. and McGill, I., 2007. Facilitating reflective learning in higher education. McGraw-Hill Education (UK).

Brydon-Miller, M., Greenwood, D., \& Maguire, P. (2003). Why action research? Action Research, 1(1), 9-28. https://doi. org/10.1177/14767503030011002.

Burchell, K., Rettie, R., Roberts, T. (2012) Practice and energy know-how. 4S-EASST Conference, Copenhagen, Denmark, 20 October 2012.

Burgess, J., \& Nye, M. (2008). Re-materialising energy use through transparent monitoring systems. Energy Policy, 36(12), 4454-4459. https://doi.org/10.1016/j. enpol.2008.09.039.

Burholt, V., \& Windle, G. (2006). Keeping warm? Selfreported housing and home energy efficiency factors impacting on older people heating homes in North Wales. Energy Policy, 34(10), 1198-1208. https://doi. org/10.1016/j.enpol.2004.09.009.

Cames, M. and Brohmann, B., 2003. Options and potentials of energy diaries: energy diaries as a tool for identifying potential energy savings through behavioural changes. Time to turn down energy demand, 1079-1090.

Darby S. (2006). The effectiveness of feedback on energy consumption - a review for Defra of the literature on metering energy consumption.

Darby S.J. \& Liddell C. (2015) Communicating 'smartness': smart meter installers in UK homes. 1991-2001, European Council for an Energy-Efficient Economy summer study, Hyres, France.

Deline, M. B. (2015). Energizing organizational research: advancing the energy field with group concepts and theories. Energy Res Soc Sci, 8, 207-221. https://doi.org/10.1016/j. erss.2015.06.003.

Devine-Wright, P., 2007. Energy citizenship: psychological aspects of evolution in sustainable energy technologies. Governing technology for sustainability, 63.

DeWaters, J. E., \& Powers, S. E. (2011). Energy literacy of secondary students in New York State (USA): A measure of knowledge, affect, and behavior. Energy Policy, 39(3), 1699-1710. https://doi.org/10.1016/j. enpol.2010.12.049.

Dixon, G. N., Deline, M. B., Mccomas, K., Chambliss, L., \& Hoffmann, M. (2015). Saving energy at the workplace: the salience of behavioral antecedents and sense of community. Energy Research and Social Science, 6, 121-127. https://oi. org/10.1016/j.erss.2015.01.004. 
Dummer, T. J., Cook, I. G., Parker, S. L., Barret, G. A., \& Hull, A. P. (2008). Promoting and assessing 'deep learning' in geography fieldwork: an evaluation of reflective field diaries. Journal of Geography in Higher Education, 32(3), 459479. https://doi.org/10.1080/03098260701728484.

Ehrhardt-Martinez, K., Donnelly, K. A., \& Laitner, S. (2010). Advanced metering initiatives and residential feedback programs: a meta-review for household electricity-saving opportunities. Washington, DC: American Council for an Energy-Efficient Economy.

Evans, J., Jones, R., Karvonen, A., Millard, L., \& Wendler, J. (2015). Living labs and co-production: university campuses as platforms for sustainability science. Current Opinion in Environmental Sustainability, 16, 1-6. https://doi. org/10.1016/j.cosust.2015.06.005.

Gupta R., Barnfield L., (2017) Exploring innovative community and household energy feedback approaches. Building Research \& Information.

Hargreaves, T. (2011). Practice-ing behaviour change: applying social practice theory to pro-environmental behaviour change. Journal of Consumer Culture, 11(1), 79-99. https://doi.org/10.1177/1469540510390500.

Hargreaves T. (2017) Beyond Energy Feedback. Building Research \& Information.

Hargreaves, T., Nye, M., \& Burgess, J. (2010). Making energy visible: a qualitative field study of how householders interact with feedback from smart energy monitors. Energy Policy, 38(10), 6111-6119. https://doi.org/10.1016/j. enpol.2010.05.068.

Hein G. (1991). Constructivist learning theory. Retrieved from http://exploratorium.edu/ifi/resources/ constructivistlearning.html

Hobson, K. (2013). On the making of the environmental citizen. Environmental Politics, 22(1), 56-72. https://doi. org/10.1080/09644016.2013.755388.

Hope, M. (2009). The importance of direct experience: a philosophical defence of fieldwork in human geography. Journal of Goegraphy in Higher Education, 33(2), 169-182. https://doi.org/10.1080/03098260802276698.

Janda B., Bull, R (2017) Challenges and opportunities for widening participation in organisational energy management. Building Research \& Information.

Jenkins, D. P. (2010). The value of retrofitting carbon-saving measures into fuel poor social housing. Energy Policy, 38(2), 832839. https://doi.org/10.1016/j.enpol.2009.10.030.

Kolb, D.A., 2014. Experiential learning: experience as the source of learning and development. FT press.

Kollmus, A., \& Agyeman, J. (2002). Mind the gap: why do people act environmentally and what are the barriers to proenvironmental behavior? Environmental Education Research, 8(3), 239-260. https://doi.org/10.1080 $/ 13504620220145401$

Lave, J., \& Wenger, E. (1991). Situated learning. Legitimate peripheral participation. Cambridge: University of Cambridge Press.

Leygue, C., Ferguson, E., Skatova, A., \& Spence, A. (2014). Energy sharing and energy feedback: affective and behavioural reactions to communal energy displays. Frontiers in Energy Research, 2, 29.

Liedtke, C., Jolanta Welfens, M., Rohn, H., \& Nordmann, J. (2012). LIVING LAB: user-driven innovation for sustainability. International Journal of Sustainability in Higher Education, 13(2), 106-118. https://doi.org/10.1108 /14676371211211809.

Lo, S. H., Peters, G.-J. Y., \& Kok, G. (2012). A review of determinants of and interventions for pro-environmental behaviours in organisations. Journal of Applied Social Psychology, 42(12), 2933-2967. https://doi.org/10.1111 /j.1559-1816.2012.00969.x.

Mezirow, J. (2009). An overview of transformative learning. In K. Illeris (Ed.), Contemporary theories of learning (pp. 90-105). Abingdon: Routledge.

Michie, S., Atkins, L. and West, R., 2014. The behaviour change wheel: a guide to designing interventions. Silverback Publishing.

Osbaldiston, R., \& Schott, J. P. (2012). Environmental sustainability and behavioural science: meta-analysis of proenvironmental behaviour experiments. Environment and Behaviour, 44(2), 257-299. https://doi.org/10.1177 /0013916511402673.

Park, C. (2003). Engaging students in the learning process: the learning journal. Journal of Geography in Higher Education, 27(2), 183-199. https://doi.org/10.1080/03098260305675.

Pedler, M., 2011. Action learning in practice. Gower Publishing, Ltd.

Royston, S. (2014). Dragon-breath and snow-melt: know-how, experience and heat flows in the home. Energy Research \& Social Science, 2, 148-158. https://doi.org/10.1016/j. erss.2014.04.016.

Shove, E., Watson, M., Ingram, J., \& Hand, M. (2007). The design of everyday life. Oxford: Berg. https://doi.org/10.5040 19781474293679.

Shove, E., Pantzar, M., \& Watson, M. (2012). The dynamics of social practice: everyday life and how it changes. London: SAGE.

Simcock, N., MacGregor, S., Catney, P., Dobson, A., Ormerod, M., Robinson, Z., Ross, S., Royston, S., \& Hall, S. M. (2014). Factors influencing perceptions of domestic energy information: content, source and process. Energy Policy, 65, 455-464. https://doi.org/10.1016/j.enpol.2013.10.038.

Sivak, M., \& Schoettle, B. (2012). Eco-driving: strategic, tactical, and operational decisions of the driver that influence vehicle fuel economy. Transport Policy, 22, 96-99. https://doi. org/10.1016/j.tranpol.2012.05.010.

Staddon, S. C., Cycil, C., Goulden, M., Leygue, C., \& Spence, A. (2016). Intervening to change behaviour and save energy in the workplace: a systematic review of available evidence. Energy Research \& Social Science, 17, 30-51. https://doi. org/10.1016/j.erss.2016.03.027.

Staddon S. (2017), Reflecting on personal and professional energy stories in energy demand management. Energy Research \& Social Science (in press)

Strengers, Y. (2013). Smart energy technologies in everyday life: smart utopia? Basingstoke: Palgrave Macmillan. https://doi. org/10.1057/9781137267054.

Thoyre, A., \& Harrison, C. (2016). Introduction: teaching energy geographies. Journal of Geography in Higher Education, 40(1), 31-38. https://doi.org/10.1080 /03098265.2016.1132539.

Van der Horst, D., Harrison, C., Staddon, S., \& Wood, G. (2016). Improving energy literacy through student-led fieldwork-at 
home. Journal of Geography in Higher Education, 40(1), 67-76. https://doi.org/10.1080/03098265.2015.1089477.

Venkataraman, B. (2009). Education for sustainable development. Environment: Science and Policy for Sustainable Development, 51(2), 8-10.

Wade, F., Hitchings, R., \& Shipworth, M. (2016). Understanding the missing middlemen of domestic heating: installers as a community of professional practice in the United Kingdom. Energy Research \& Social Science, 19, 39-37. https://doi. org/10.1016/j.erss.2016.05.007.

Wade, F., Shipworth, M., \& Hitchings, R. (2017). How installers select and explain domestic heating controls. Building Research \& Information, 45(4), 371-383. https://doi. org/10.1080/09613218.2016.1159484.

Wallenborn, G., \& Wilhite, H. (2014). Rethinking embodied knowledge and household consumption. Energy Research
\& Social Science, 1, 56-64. https://doi.org/10.1016/j. erss.2014.03.009.

Wilhite, H. L., \& Wilke, R. (1987). A method for self-recording household energy-use behavior. Energy and Buildings, 10(1), 73-79. https://doi.org/10.1016/0378-7788(87)90007-7.

Wilhite, H., Nakagami, H., Masuda, T., Yamaga, Y., \& Haneda, H. (1996). A cross-cultural analysis of household energy use behaviour in Japan and Norway. Energy Policy, 24(9), 795803. https://doi.org/10.1016/0301-4215(96)00061-4.

Wood, G., van der Horst, D., Day, R., Bakaoukas, A. G., Petridis, P., Liu, S., Jalil, L., Gaterell, M., Smithson, E., Barnham, J., \& Harvey, D. (2014). Serious games for energy social science research. Technology Analysis \& Strategic Management, 26(10), 1212-1227. https://doi. org/10.1080/09537325.2014.978277. 